\title{
Comparison of PCCC Performance in Presence of Mercaptans and DBDS Sulfur in Transformer Oil Using Ø-t-N Technique
}

\author{
L. Sanjeev Kumar ${ }^{1}$, B.Ramachandra ${ }^{2}$, S. Senthil Kumar ${ }^{3}$ \\ Professor, Electrical and Electronics Engg, Sri Siddhartha Institute of Technology, Tumakuru, Karnataka, India ${ }^{1}$ \\ Professor, Electrical and Electronics Engg, PES College of Engg, Mandya, Karnataka, India ${ }^{2}$ \\ Head Intellectual Property ABB, Bengaluru, Karnataka, India ${ }^{3}$
}

\begin{abstract}
Paper-oil insulation is widely used in transformers. The reactive sulfur forms copper sulfide and dispersing in oil causes the reduction in insulation of the transformer. It is reported that during life cycle of transformer, paper and pressboard insulation undergoes deterioration mainly because of increase in sulfur content in transformer oil. The types of reactive sulfur that are present in transformer oil are Mercaptans (2-MBT) and di-benzo-di-sulfide (DBDS). The $\varnothing$-t-N distribution is a popular choice for PD representation as the discharge magnitude is associated with the state of insulation. Representations based on the charge magnitude are susceptible to influence of the measuring system, discharge and equivalent characteristics. On the other hand, the $\varnothing$-t-N representation offers much flexibility hence this method is chosen to compare the performance of PCCC under the influence of different sulfur contamination.
\end{abstract}

Keywords: PD, Sulfur corrosion, paper-oil insulation, Mercaptan sulfur, DBDS sulfur.

\section{INTRODUCTION}

The reliability of power transformers is normally high and their expected life time typically exceeds 30 years. A recent observation of premature transformer failures in the field caused by copper sulfide deposition has raised a large interest in the power industry [1]. The Transformer often fails in the system causing undesirable instability of the power system. Transformer oil is a mineral oil containing organic and sulfur compounds $[1,2]$. Sulfur is commonly found in crude oil source. Elemental sulfur and the sulfurcontaining Mercaptans are very reactive followed by sulfides. It is observed that non corrosive sulfur can become corrosive after being exposed to elevate temperatures on hot metal surfaces and thus produce metal sulfides. The effects of corrosive / reactive sulfur not only adversely affect the conductor material and other metal surfaces but also can have drastic effects on insulating materials such as paper [3, 4]. The serious contamination due to sulfur-containing surfaces can drastically reduce the dielectric strength of the paper insulation. The paper insulation is damaged due to these discharges and leads to breakdown of insulation. In this study, samples of paper covered copper conductors (PCCC) are subjected electric stress. Mercaptan sulphur / DBDS sulfur is added to oil to create the contamination for investigation. The discharge characteristics of the insulation were also studied for establishing correlation between copper corrosion and partial discharge [PD] characteristics using $\varnothing$-t-N technique. The $\varnothing$-t-N distribution is constituted by time related parameters which can be precisely measured. $\varnothing$-t$\mathrm{N}$ distribution has time interval parameter represented in sequence can be used for pulse correlation and study pulse behaviour along the phase angle therefore it has pulse to pulse correlation values present in the natural sequence of occurrence along the phase angle in the pattern.
Once began, PD causes progressive deterioration of insulating materials, ultimately leading to electrical breakdown. The effects of PD within high voltage equipment can be very serious, ultimately leading to complete failure. The chemical transformation of the dielectric also tends to increase the electrical conductivity of the dielectric material surrounding the voids. This increases the electrical stress in the unaffected gap region, accelerating the breakdown process.

\section{DETAILS OF EXPERIMENTS}

The main objective of this study was to replicate the environment of power transformer with paper oil insulation. Straight detection method was used for the measurement of PD. The schematic diagram of the PD measuring setup is shown in fig.1. A high voltage transformer $(10 \mathrm{kVA}, 230 / 100 \mathrm{kV}$, WS test systems make Bangalore) used for applying high voltage across the specimen.

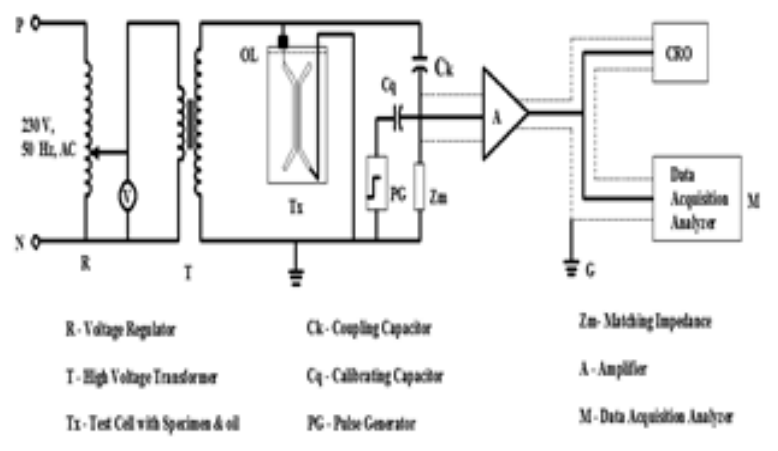

Fig.1: Block Diagram of PD Measuring System 
INTERNATIONAL JOURNAL OF INNOVATIVE RESEARCH IN ELECTRICAL, ELECTRONICS, INSTRUMENTATION AND CONTROL ENGINEERING Vol. 4, Issue 1, January 2016

The PD data Acquisition system receives the PD signals from an Amplifier, which is sensed by coupling capacitance $\mathrm{Cc}$, due to the discharges in the test sample. The discharge parameters measured and stored in computer system for further analysis.

SAMPLE PREPARATION: the PCCC is configured in pigtail arrangement as shown in figure 2. Two copper conductors each of $9 \mathrm{~mm}$ width, $3.5 \mathrm{~mm}$ thickness and length $130 \mathrm{~mm}$ are used. The pig-tail comprising of three portions namely, straight portion of length $100 \mathrm{~mm}$ at the centre with two bend portions of $15 \mathrm{~mm}$ on either side making an angle of $30^{\circ}$ with the horizontal are joined together and held firmly by wrapping of PTFE tape at the two ends of the straight portion. The conductors are wrapped with either 3 layer of $0.055 \mathrm{~mm}$ thickness Kraft paper insulation. The paper insulation used confirm to IEC-554-3-5 (1984) (Rev.3) standards for the transformers. The pig-tail specimen is dried at a temperature of $1000 \mathrm{C}$ for 12 Hours.

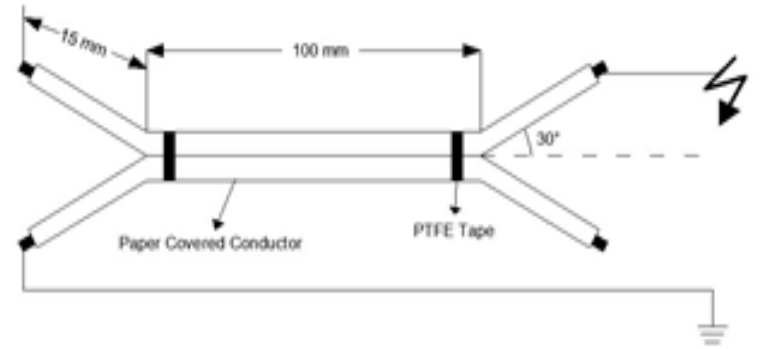

Figure.2: Pig-tail configuration of sample.

\section{MEASUREMENTS}

The pigtail insulation was subjected to voltage stress in test cell. The measurements on sample included measurement of partial discharge including PD inception, PD extinction, discharge magnitudes and number of pulses for each cycle. Measurements were made with treated transformer oil and sulphur contaminated $(50 \mathrm{ppm}$ and $100 \mathrm{ppm}$ of Mercaptan sulphur and 200ppm and 300ppm DBDS sulfur) Transformer oil. The PD parameters are recorded over duration of $1 \mathrm{sec}$ contentiously for 14400 sec with a pause of $10 \mathrm{sec}$ between the record, for 1.4times PD inception voltage and allowing a stabilization period of 60 seconds.

\section{RESULTS AND DISCUSSIONS}

The inception and extinction voltage of pure and Mercaptan sulphur / DBDS sulfur contaminate oil are shown in fig. 3 and 4 respectively.

The $\Phi$-q-n distribution is a popular choice for PD representation as the discharge magnitude is associated with the state of the insulation. On the other hand $\Phi-\mathrm{t}-\mathrm{n}$ representation offers much flexibility [12]. The $\Phi-\mathbf{t}-\mathbf{n}$ distribution is constituted by time related parameters which can be precisely measured. $\Phi-\mathrm{t}-\mathrm{n}$ distribution has time interval parameter represented in sequence that can be used for pulse correlation and study pulse behaviour along the phase angle therefore it has pulse to pulse correlation values present in the natural sequence of occurrence along the phase angle in the pattern.

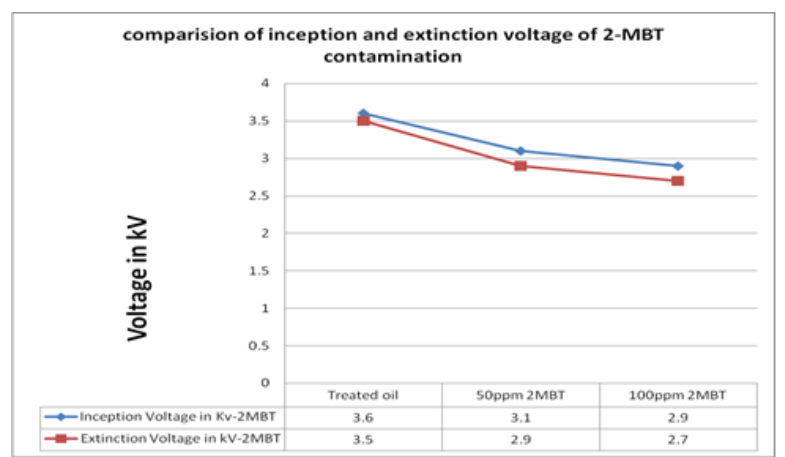

Figure 3: variation of inception and extinction voltage in pure and 2-MBT contaminated oil

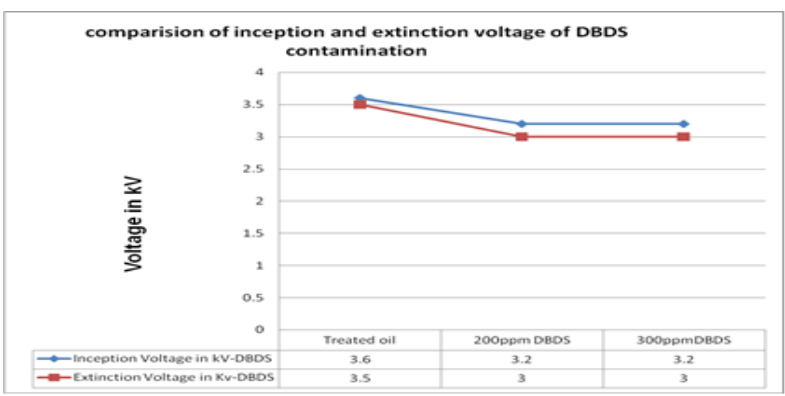

Figure 4: variation of inception and extinction voltage in pure and DBDS contaminated oil

$\Phi$-t-n distribution pattern is based on phase and time interval parameters. Phase information represents field symmetry and type of discharge while the time interval information can reveal physical process of discharge. The $\Phi-\mathrm{t}-\mathrm{n}$ representation is simple and processes superior fingerprint attributes compared to the popularly used $\Phi$-q$\mathrm{n}$ distribution. The distribution is obtained by representing $n$th pulse in a sequence by time interval $(\Delta \mathrm{tn})$ and phase position $(\Phi n)$ where $\Delta$ tn $=\Phi n+1-\Phi n$. The $\Phi-\mathrm{t}-\mathrm{n}$ distribution will show the intra-cluster pulse and intercluster pulses as shown in figure.5.

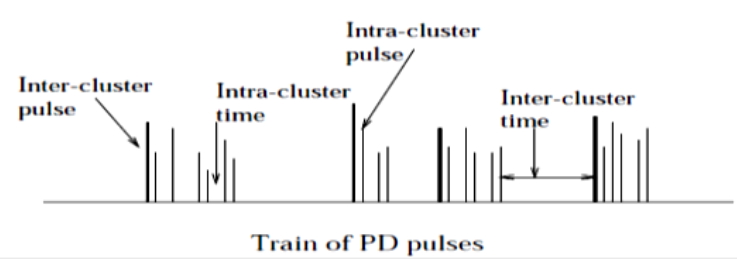

Figure 5: Train of PD pulses

$\Phi$-t-n variation is plotted separately for pure and Mercaptan sulphur / DBDS sulfur contaminate oil transformer oil. The $\Phi-\mathrm{t}-\mathrm{N}$ results to analyse the behaviour of the insulation under different oil conditions are shown as follows:

(i) Pure transformer oil

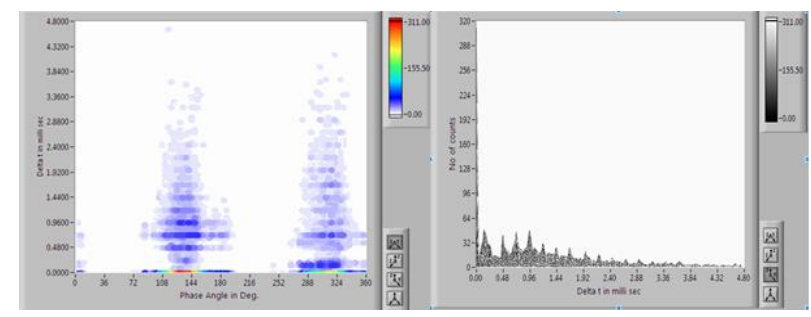


Vol. 4, Issue 1, January 2016

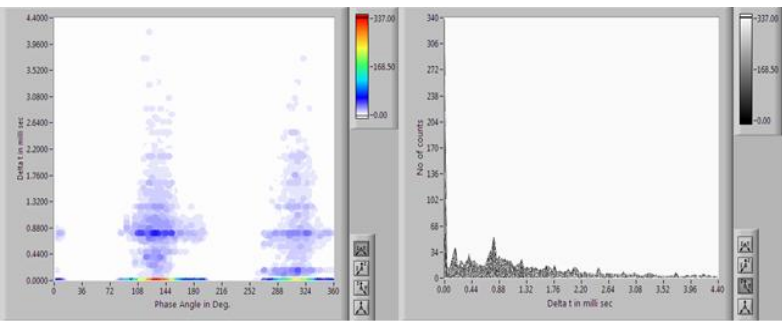

(ii) Mercaptan sulphur contaminate oil with (a) $50 \mathrm{ppm}$ level
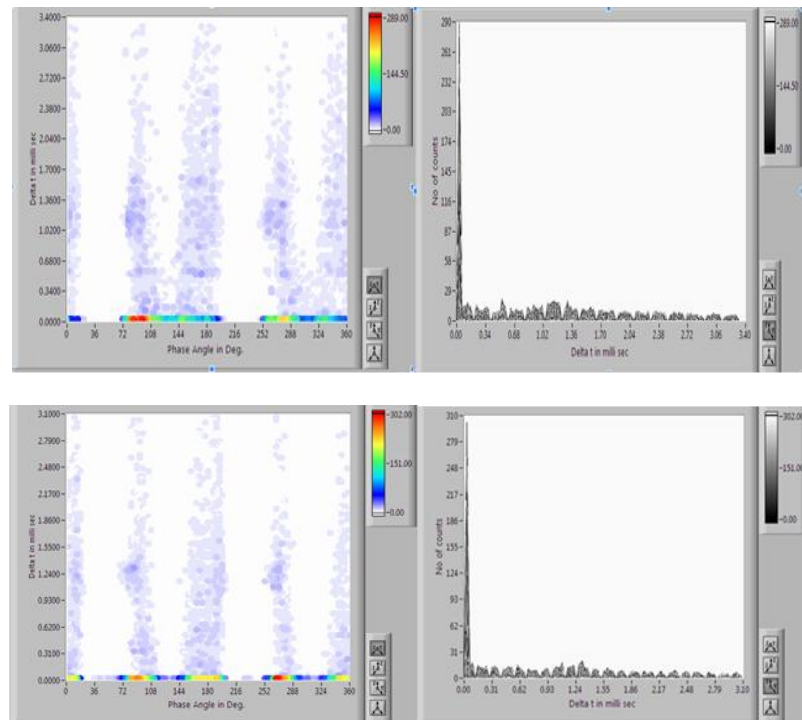

(b) 100ppm level
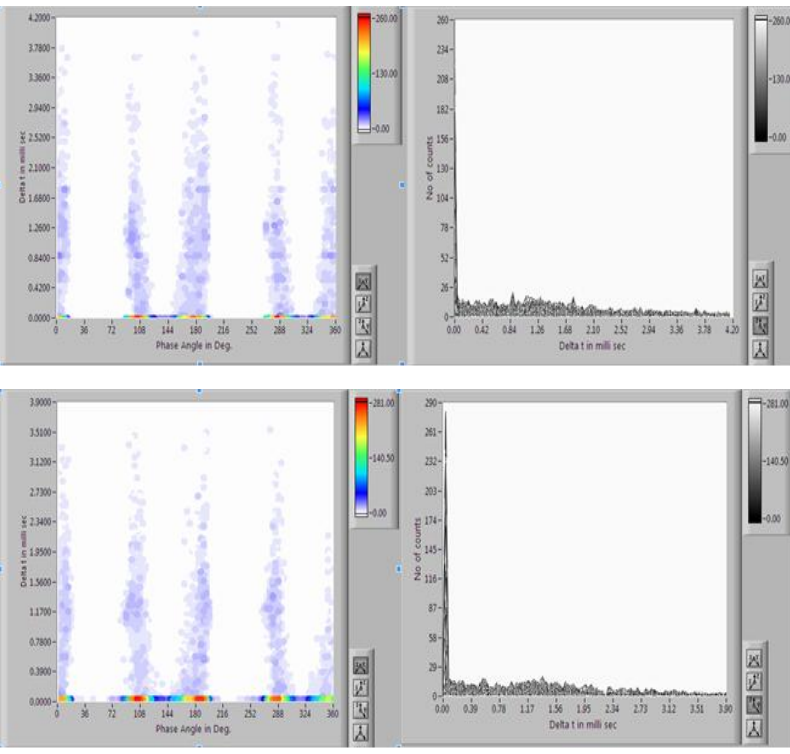

(iii) DBDS sulphur contaminate oil with

(a) 200ppm

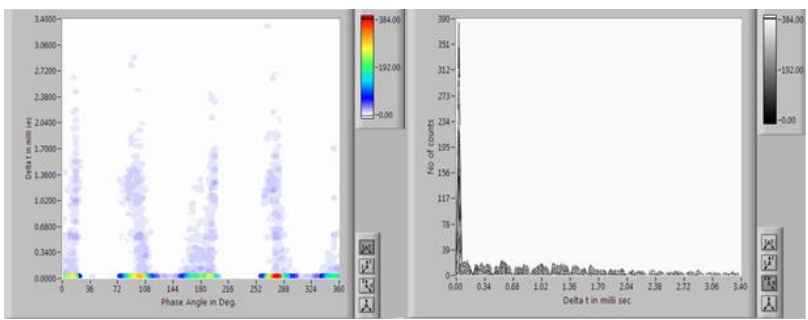

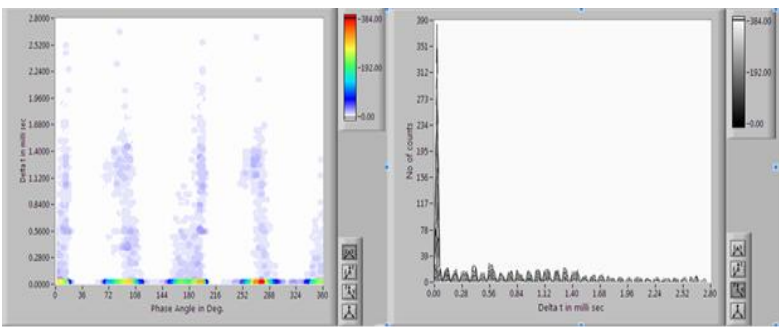

(b) $300 \mathrm{ppm}$
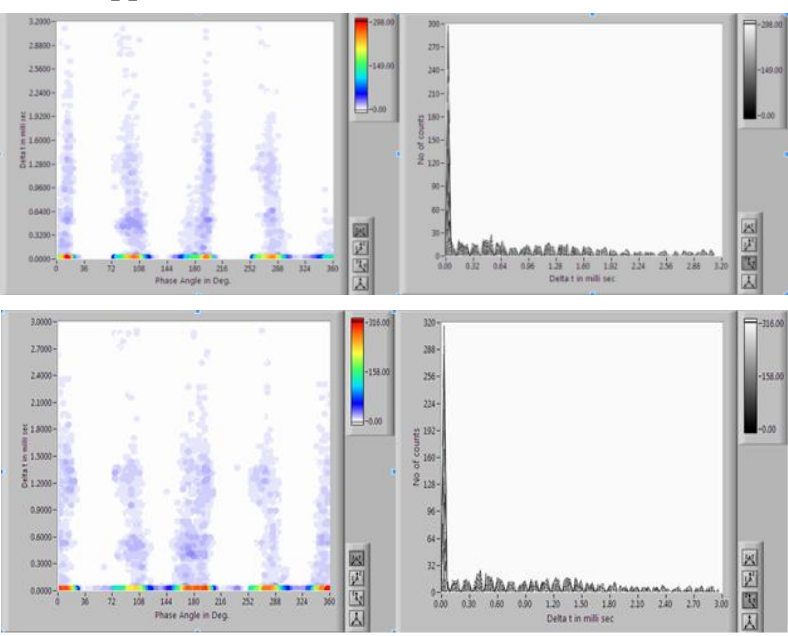

The time of intra-cluster pulses (inter pulses time of occurrence) will decreases with type of contamination and level of contamination. This is shown in the table 1 , the number of pulses occur in positive cycle is more and increases as the time of experiment increases. The above factor indicates the deterioration in insulation of the Paper Covered Copper Conductor subjected to the type and level of contamination of oils. The pulse count information (third dimension in the distribution) is not significant in $\Phi$ t-n representation for PD knowledge, a possibility of conversion of the $3 \mathrm{D}$ pattern to a $2 \mathrm{D}$ pattern opens up for simple representation. This $2 \mathrm{D}$ representation gives the information about the intra-pulse behaviour of PD.

\begin{tabular}{|c|c|c|c|c|}
\hline \multicolumn{2}{|c|}{$\begin{array}{l}\text { Type of the } \\
\text { oil }\end{array}$} & $\begin{array}{l}\text { Time at } \\
\text { starting of } \\
\text { experiment } \\
\text { in } \mathrm{m} \\
\text { seconds }\end{array}$ & $\begin{array}{l}\text { Time at } \\
\text { ending of } \\
\text { experiment } \\
\text { in } \mathrm{m} \\
\text { seconds }\end{array}$ & Remarks \\
\hline \multicolumn{2}{|c|}{$\begin{array}{l}\text { Pure } \\
\text { transformer } \\
\text { oil }\end{array}$} & 7.2 & 4.4 & $\begin{array}{l}\text { No "U" } \\
\text { shape } \\
\text { indicating no } \\
\text { corona }\end{array}$ \\
\hline \multirow{2}{*}{ 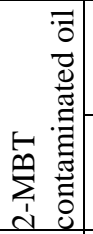 } & $\begin{array}{l}50 \\
\mathrm{ppm}\end{array}$ & 6.5 & 3.3 & $\begin{array}{l}\text { Corona starts } \\
\text { after some } \\
\text { time }\end{array}$ \\
\hline & $\begin{array}{l}100 \\
\text { ppm }\end{array}$ & 6.9 & 3.7 & $\begin{array}{l}\text { Corona starts } \\
\text { after some } \\
\text { time }\end{array}$ \\
\hline \multirow{2}{*}{ 乞 } & $\begin{array}{l}200 \\
\text { ppm }\end{array}$ & 3.6 & 2.8 & $\begin{array}{l}\text { Corona starts } \\
\text { immediately }\end{array}$ \\
\hline & $\begin{array}{l}300 \\
\mathrm{ppm}\end{array}$ & 3.7 & 2.9 & $\begin{array}{l}\text { Corona starts } \\
\text { immediately }\end{array}$ \\
\hline
\end{tabular}

Table 1: change in time of intra-pulses in different oil conditions 


\section{CONCLUSION}

From this study we can observe and conclude as follows:

$>$ The $\Phi$-t-n representation in 2D shows inverted " $U$ " shape indicating corona discharges [senthil].

$>$ The pattern becomes sharp with change in time and shape remaining constant indicating increasing the stress on insulation.

$>$ The reduction of time from starting of experiment to ending of experiment is more in contaminated oil than pure transformer oil.

$>$ This reduction of time is responsible for deterioration of the insulation due to the presence of copper sulfide.

$>$ The type of contamination and level of contamination has more impact on the performance of insulation.

\section{ACKNOWLEDGEMENT}

The Author would like to thank Dr. B.V. Sumangala, Professor and Head, Department of Electrical and Electronics Engineering Dr.A.I.T. Bengaluru for providing the opportunity to conduct the Experiments in their laboratory. Author also extends gratitude to Dr. J. Sundara Rajan CCAR-Central Power Research Institute, Bangalore and Dr. G. Parameshwara, Joint Secretary, SSES who has encouraged and provided the opportunity for carrying out research work.

\section{REFERENCES}

[1.] CIGRE WG-A2-32, "Copper sulphide in transformer insulation", Final Report, 2009

[2]. C. Bengtsson et.al "Oil Corrosion and $\mathrm{Cu}$ Cu2S Deposition in Power Transformers", CIGRE Moscow Symposium 2005.

[3.] Report WG A2.32, "Copper sulphide in Transformer Insulation", No.230, February 2007, Electra, PP.12-17.

[4.] Report from CIGRE TF A2-31, "Copper Sulphide in Transformer Insulation ", Cigre, Copy of report to be published in Electra, February 2006 issue.

[5.] J. Sundara Rajan “ Partial Discharge Phenomena in Paper Insulation Under Conditions of Copper Insulation due to Sulphur in oil" Proceedings of the 9th International Conference on Properties and Applications of Dielectric Materials July 1923,2009, Harbin, China

[6.] Dr. F.H.Kreuger, "Partial Discharge Detection in High Voltage Equipment", Butterworth \& co.(publisher) Ltd 1989.

[7.] S. Sentil Kumar, Y.P. Narayanachar and R.S. Neema 'Response of Narrow Band Detector and Analyzer to Ageing Experiment', IEEE Conference on Electrical Insulation and Dielectric Phenomina (2002 CEIDP), Cancun, Quintana Roo, Mexico,(October 20-24, 2002)

[8.] Paul J, Griffin and Lance R. Lewand, "Understanding Corrosive sulfur Problems in Electric Apparatus ", Doble Engineering Company Proceedings of 74th Annual International Doble Client conference 2007.

[9.] Cavallini, A. Analysis of partial discharge phenomena in paper-oil insulation systems as a basis for risk assessment evaluation" IEEE International Conference on Dielectric Liquids, 2005. ICDL 2005. 200526 June-1 July 2005, P241 - 244

[10.] Raja, M.N. Narayanachar and R.S. Nema "A Study of Phase Angle Distribution of Partial Discharges in Oil Pressboard Insulation Systems"

[11]. Lance R. Lewand Doble Engineering Company, USA" The Role of Corrosive Sulfur in Transformers and Transformer Oil" 2002 Doble Engineering Company

[12.] S.Senthil Kumar, M.N.Narayanachar and R.S.Nema: "Partial Discharge Pulse Sequence Analyses - A New Representation of Partial Discharge Data" High Voltage Engineering Symposium, Conference Publication No. 461, of IEEE 21-22 August 1999.
[13] L.Sanjeev Kumar, Ramachandra.B., S.Senthil Kumar, "Performance of PCCC in presence of mercaptans in transformer oil using Ø-t-N technique" International Conference on Power and Advanced Control Engineering (ICPACE), 2015 IEEE Xplore 1214 Aug. 2015, Bangalore, pages 393 - 398

\section{BIOGRAPHIES}

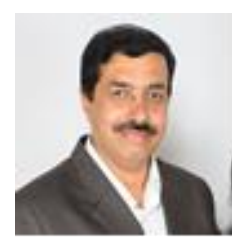

Sanjeev Kumar. L completed his Engg. From PESCE Mandya, Masters from NIE Mysore, presently pursuing Ph.D. from Kuvempu University. Working in SSIT Tumakuru from 1990 .

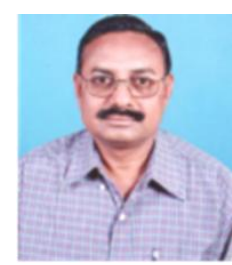

Dr. B. Ramachandra working as Professor and Head in EED, PESCE Mandya. He had his PhD From IISc. Bangalore, Master's from IIT-Bombay. He has about 25 scientific publications in this area. He is also academic active, guiding research students and interacting with universities

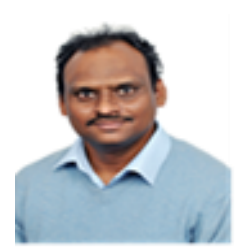

Dr. S. Senthil Kumar working as Head Intellectual property at ABB Bengaluru. Obtained his Master's and Ph.D. from IISc. Bengaluru. He has about 30 scientific publications in this area. He is also academic active, guiding research students and interacting with universities. 